\title{
A PRESENÇA DE ESTUDANTES INDÍGENAS NA UNIVERSIDADE FEDERAL DE SANTA CATARINA: UM PANORAMA A PARTIR DO PROGRAMA DE AÇÕES AFIRMATIVAS - PAA/UFSC
}

\author{
THE PRESENCE OF INDIGENOUS STUDENTS AT THE \\ FEDERAL UNIVERSITY OF SANTA CATARINA: \\ AN OVERVIEW FROM THE AFFIRMATIVE ACTION \\ PROGRAM - AAP / UFSC
}

\author{
Antonella Maria Imperatriz Tassinari* \\ Edwiges Marta Ioris** \\ José Nilton de Almeida*** \\ Suzana Cavalheiro de Jesus****
}

RESUMO: O artigo aborda uma avaliação do Programa de Ações Afirmativas (PAA) da Universidade Federal de Santa Catarina (UFSC), no que tange à situação de ingresso e permanência de estudantes pertencentes a povos indígenas. Para tanto, utiliza-se de levantamento bibliográfico acerca da legislação sobre ações afirmativas; de informações institucionais coletadas junto à Comissão Permanente do Vestibular (COPERVE) e ao Departamento de Administração Escolar (DAE); e de relatos feitos pelos estudantes indígenas em consultas realizadas em 2010, 2011 e 2012 por bolsistas Capes/ REUNI do Programa de Pós-Graduação em Antropologia Social da UFSC. Esse conjunto de informações permitiu traçar um panorama acerca da relação dos indígenas com a Universidade Federal de Santa

\footnotetext{
* Doutora em Antropologia Social, Professora do Departamento de Antropologia da Universidade Federal de Santa Catarina e membro da Comissão de Acompanhamento e Avaliação do Programa de Ações Afirmativas da UFSC; Florianópolis, SC, Brasil; e-mail: antonell@cfh.ufsc.br

** Doutora em Antropologia Social, Professora do Departamento de Antropologia da Universidade Federal de Santa Catarina e coordenadora o Núcleo de Estudos de Povos Indígenas - NEPI-UFSC; Florianópolis, SC,Brasil; e-mail: emioris@gmail.com

*** Doutor em Educação, Professor do Departamento de Educação da Universidade Federal Rural de Pernambuco - UFRPE; Recife, PE, Brasil; e-mail: joseniltondealmeida@gmail.com

**** Doutoranda em Antropologia Social no Programa de Pós Graduação em Antropologia Social da Universidade Federal de Santa Catarina - UFSC; Florianópolis, SC, Brasil; e-mail: suzanacavalheiro@yahoo.com.br
}

212| Século XXI, Revista de Ciências Sociais, v.3, nº 1, p.212-236, jan./jun. 2013 ISSN: 2236-6725 
Catarina e viabilizou a elaboração de sugestões, levadas à Comissão de Acompanhamento e Avaliação do Programa de Ações Afirmativas, como parte do processo de avaliação institucional do PAA. Tais elementos, também expressos neste artigo, visam ainda contribuir com as discussões presentes no cenário atual das instituições de ensino superior brasileiras e suas adequações à recente Lei 12.711 de 29 de agosto de 2012, também conhecida como "Lei de Cotas".

Palavras-chaves: ensino superior, ações afirmativas, povos indígenas, interculturalidade, democratização.

ABSTRACT: The paper reports on an evaluation of the Affirmative Action Program (PAA) at the Federal University of Santa Catarina - UFSC, in regard to the situation of entry and permanence of students belonging to indigenous peoples. To do so, we use the literature concerning the legislation on affirmative action; institutional information collected by the Standing Committee of the Vestibular (COPERVE) and the Department of School Administration (DAE) and reports made by indigenous students in consultations in 2010, 2011 and 2012 by scholars Capes/REUNI students at the program post-graduation in Social Anthropology at UFSC. This set of data allowed to give an overview of the relation of indigenous peoples with the Federal University of Santa Catarina and allowed the elaboration of suggestions brought to the Affirmative Action Commission, as part of the process of institutional assessment PAA. These elements expressed in this article, also aim to contribute to the discussions present in the current scenario of the Brazilian higher education institutions and their adaptations to the recent Law 12,711 of August 29, 2012, known as "Quota Law".

Keywords: higher education, affirmative action, indigenous, intercultural, democratization.

\section{INTRODUÇÃO}

O presente artigo foi escrito a partir de uma análise elaborada pelos autores, no contexto do Núcleo de Estudos de Povos Indígenas 
(NEPI) da Universidade Federal de Santa Catarina (UFSC). Tal análise constou de um relatório com vistas a subsidiar a Comissão de Acompanhamento e Avaliação do Programa de Ações Afirmativas, no que tange às questões de ingresso e permanência de estudantes indígenas através do Programa de Ações Afirmativas (PAA) da instituição. Inicialmente foi realizado um diagnóstico dos índices de ingresso e permanência desses estudantes a partir de um levantamento bibliográfico; de informações institucionais oriundas da Comissão Permanente do Vestibular (COPERVE) acerca de inscrição e desempenho no vestibular; do Departamento de Administração Escolar (DAE) sobre as situações de matrículas e das comissões de validação da autodeclaração de indígenas; e dos próprios estudantes indígenas a partir de consultas realizadas entre os anos 2010 e 2012 com aqueles efetivamente matriculados, bem como com estudantes Guarani que não obtiveram êxito no vestibular. Estas consultas foram feitas por bolsistas CAPES/REUNI do Programa de Pós-Graduação em Antropologia Social da UFSC ${ }^{1}$, como parte de seus planos de atividades ${ }^{2}$. Além destes levantamentos, o diagnóstico contou com informações oriundas das discussões conduzidas, especialmente, em dois eventos: no Seminário Ações Afirmativas na UFSC, promovido pelo Instituto Nacional de Ciência e Tecnologia de Inclusão no Ensino Superior e Pesquisa; e no Seminário Educação Superior Indígena: Desafios para UFSC, promovido pelo NEPI e pelo Instituto Nacional de Ciência e Tecnologia Brasil Plural, que ocorreram, respectivamente, em 16 e em 31 de outubro de 2011.

Esse conjunto de informações e discussões tanto com os indígenas, quanto com os promotores das Ações Afirmativas nos per-

\footnotetext{
${ }^{1}$ Os bolsistas REUNI envolvidos nessa pesquisa foram: Paola Gibran, Brisa Catão Totti e Viviane Vasconcelos (2010), Suzana Cavalheiro de Jesus (2011), Ana Carolina Rocha, Celso Senna Alves Neto, Gabriella de Souza, (2012).

${ }^{2}$ Esta bolsa da Coordenação de Aperfeiçoamento de Pessoal de Nível Superior (CAPES) do Governo Federal é paga aos estudantes de pós-graduação através de recursos do Programa de Apoio a Planos de Reestruturação e Expansão das Universidades Federais Brasileiras (REUNI). O objetivo desse programa é "criar condições para a ampliação do acesso e permanência na educação superior, no nível de graduação, pelo melhor aproveitamento da estrutura física e de recursos humanos existentes nas universidades federais" (Decreto ${ }^{\circ}$ 6.096, de 24 de abril de 2007). Para tanto, estabelece seis diretrizes de trabalho, dentre essas o "suporte da pós-graduação ao desenvolvimento e aperfeiçoamento qualitativo dos cursos de graduação" (Ibid.).
}

214| Século XXI, Revista de Ciências Sociais, v.3, nº 1, p.212-236, jan./jun. 2013 ISSN: 2236-6725 
mitiu elaborar um quadro bastante elucidativo sobre os indígenas na sua relação com a UFSC. Do mesmo modo, nos permitiu elencar sugestões, levadas à Comissão de Acompanhamento e Avaliação do Programa de Ações Afirmativas, a fim de otimizar os esforços que assegurem a eles o acesso e a permanência no Ensino Superior.

Baseado na análise acima descrita, este artigo visa elucidar, em uma primeira seção, a política atual de ações afirmativas adotada na UFSC. Em seguida, aborda os resultados do diagnóstico relativo às inscrições, aprovações e classificações de indígenas nos vestibulares da UFSC entre os anos de 2008 e 2012. E por fim, discute as sugestões encaminhadas à Comissão de Acompanhamento e Avaliação do Programa de Ações Afirmativas em meados no ano de 2012, período de avaliação do PAA.

\section{AÇÕES AFIRMATIVAS NO CONTEXTO DA UNIVERSI- DADE FEDERAL DE SANTA CATARINA}

Nos últimos anos, as políticas de educação superior no Brasil foram sendo aprimoradas, no que tange aos debates sobre as chamadas ações afirmativas. Segundo Cajueiro (2007), estas iniciativas estiveram baseadas no acesso diferenciado de grupos socialmente desfavorecidos à universidade. Seja por reparação histórica, incentivo à diversidade ou promoção de justiça social e da equidade educacional, a partir do ano 2000, quando foi promulgada a primeira lei estadual ${ }^{3}$ sobre reserva de vagas em universidades públicas no Brasil, uma série de iniciativas para promover esse acesso diferenciado começou a surgir nas universidades de todas as regiões do país (Cajueiro, 2007; Souza Lima e Barroso-Hoffmann, 2007). Algumas destas iniciativas foram direcionadas a um público-alvo definido segundo critérios socioeconômicos, outras segundo critérios étnico-raciais (ibid.).

Cabe destacar que até muito recentemente (agosto de 2012), as políticas de ações afirmativas em nosso país, foram regidas pela autonomia universitária, impulsionada pela luta de movimentos

\footnotetext{
${ }^{3}$ Lei $n^{\circ} 3524$, de 28 de dezembro de 2000, estado do Rio de janeiro, revogada em 2003 com a Lei $\mathrm{N}^{\circ} 4151 / 2003$.

215| Século XXI, Revista de Ciências Sociais, v.3, nº 1, p.212-236, jan./jun. 2013 ISSN: 2236-6725
} 
sociais, especialmente pelas diferentes expressões do movimento negro e, portanto, foram relacionadas às especificidades dos movimentos sociais em cada contexto regional. Somado a pontuais regulamentações em nível estadual, como o caso do estado do Rio de Janeiro, as instituições contavam, em nível federal, com o respaldo das orientações contidas no Parecer 03 e na Resolução 01 do Conselho Nacional de Educação. Estes documentos, publicados no ano de 2004, dispõem sobre As Diretrizes Curriculares Nacionais para a Educação das Relações Étnico-Raciais, as quais devem ser inseridas em todas as modalidades e níveis da Educação Básica, inclusive no Ensino Superior. Porém, carregam conteúdos que visam justificar e apoiar a necessidade de implementação de políticas de ações afirmativas, sem direcionar as ações de cada instituição. $\mathrm{O}$ texto do parecer esclarece a respeito:

"O parecer procura oferecer uma resposta, entre outras, na área da educação, à demanda da população afrodescendente, no sentido de políticas de ações afirmativas, isto é, de políticas de reparações, e de reconhecimento e valorização de sua história, cultura, identidade. Trata, ele, de política curricular, fundada em dimensões históricas, sociais, antropológicas oriundas da realidade brasileira, e busca combater o racismo e as discriminações que atingem particularmente os negros. Nesta perspectiva, propõe a divulgação e produção de conhecimentos, a formação de atitudes, posturas e valores que eduquem cidadãos orgulhosos de seu pertencimento étnico-racial - descendentes de africanos, povos indígenas, descendentes de europeus, de asiáticos - para interagirem na construção de uma nação democrática, em que todos, igualmente, tenham seus direitos garantidos e sua identidade valorizada." (Parecer CNE/CP No 3/2004, p 01).

No que tange ao ensino superior, até 2007 o Conselho Nacional de Educação estimava existir no Brasil cerca de 5.000 estudantes universitários indígenas, entre formados e formandos (Cajueiro, 2007). Considerando o perfil socioeconômico, o autor destaca que a maior parte dessa população cursou a educação básica em escolas pú- 
blicas, as quais, com raras exceções, padecem com a falta de preparo de professores e gestores para o trato da presença indígena, sendo um agravante para os problemas normalmente encontrados na escolarização de camadas populares. Há que se considerar, também, que muitos estudantes indígenas trilharam outros percursos escolares, como escolas religiosas próximas de suas aldeias. Dessa forma, é de se supor que esse contingente de estudantes universitários indígenas venha crescendo consideravelmente, tanto através de políticas de reservas de vagas, quanto de Cursos de Licenciaturas Interculturais Indígenas ${ }^{4}$.

As experiências para promover o acesso dos indígenas ao ensino superior podem ser observadas nas várias regiões do país. No contexto da Universidade Federal de Santa Catarina (UFSC), quando da criação do Programa de Ações Afirmativas, através da Resolução Normativa $\mathrm{n}^{\circ} 008 / \mathrm{CUN} / 2007$, de 10 de julho de 2007, os "estudantes pertencentes a povos indígenas" apareciam como um alunado a ser contemplado com vagas suplementares. Deste modo, ocupariam vagas que seriam criadas nos cursos escolhidos, no máximo de duas por curso, mediante aprovação do candidato no processo regular do vestibular. $\mathrm{O}$ artigo $9^{\circ}$ desse documento previa a criação de cinco vagas suplementares que seriam preenchidas pelos candidatos melhor classificados no vestibular, sendo criadas 1 nova vaga a cada ano, até um total de 10 vagas em 2013.

Apesar do pequeno número de vagas, em relação à crescente demanda de estudantes indígenas pelo Ensino Superior, dentre as 35 vagas ofertadas pela UFSC de 2008 a $2012^{5}$, somente 9 foram preenchidas $^{6}$. Neste mesmo período, completando cinco anos de existência, chegava o momento de o Programa de Ações Afirmativas ser avaliado no âmbito da instituição, processo este que veio a acontecer concomitantemente com as discussões sobre a implementação da Lei 12.711 de 29 de agosto de 2012, conhecida como "Lei de Cotas".

\footnotetext{
${ }^{4}$ Em Seminário realizado em maio de 2013 na Universidade Federal de Santa Catarina, pela Licenciatura Intercultural Indígena do Sul da Mata Atlântica, foi expresso o total de 26 licenciaturas específicas para formação de professores indígenas existentes hoje no Brasil.

${ }^{5}$ Foram oferecidas 5 vagas em 2008, 6 em 2009, 7 em 2010, 8 em 2011 e 9 em 2012, num total de 35 vagas.

${ }^{6}$ Observa-se que, dentre os 10 candidatos efetivamente matriculados ao longo do período, a mesma candidata matriculou-se em Enfermagem em 2008 e em Medicina em 2010.
}

217| Século XXI, Revista de Ciências Sociais, v.3, nº 1, p.212-236, jan./jun. 2013 ISSN: 2236-6725 
A referida legislação dispõe sobre o ingresso nas universidades federais e nas instituições federais de ensino técnico de nível médio. Estabelece que pelo menos $50 \%$ das vagas das instituições federais de educação superior, vinculadas ao Ministério da Educação, devem ser destinadas a estudantes que tenham cursado integralmente o ensino médio em escolas públicas. Metade destas deve contemplar estudantes oriundos de famílias com renda igual ou inferior a 1,5 salário mínimo per capita. Do mesmo modo, cada instituição deve preencher tais vagas:

“por curso e turno, por autodeclarados pretos, pardos e indígenas, em proporção no mínimo igual à de pretos, pardos e indígenas na população da unidade da Federação onde está instalada a instituição, segundo o último censo do Instituto Brasileiro de Geografia e Estatística” (IBGE).(Brasil, 2012, p.01)

A lei estabelece ainda o prazo de quatro anos para que as instituições possam adequar-se a esta política de reserva de vagas, ou seja, implementando o mínimo de $25 \%$ das chamadas cotas a cada ano. Esse processo de implementação deverá ser acompanhado e avaliado pelo Ministério da Educação e pela Secretaria Especial de Políticas de Promoção da Igualdade Racial, da Presidência da República, ouvida a Fundação Nacional do Índio (Funai). Em 10 anos, a contar da publicação da Lei, está prevista uma "revisão do programa especial para o acesso de estudantes pretos, pardos e indígenas, bem como daqueles que tenham cursado integralmente o ensino médio em escolas públicas" (Brasil, 2012, p 02), a ser viabilizada pelo Poder Executivo, junto às instituições de ensino superior.

Estamos assim diante de uma conquista importante dos movimentos sociais, porém, com um documento que segue critérios há tempos questionados por estes mesmos movimentos, como a autodeclaração a partir de critérios definidos pelo IBGE. Somado a isto, a Comissão de Acompanhamento e Avaliação do Programa de Ações Afirmativas da UFSC, na busca de adequar o cálculo do número de vagas à proporção prevista na "Lei de Cotas" identificou que o número de vagas para os segmentos "negros" e "pertencentes a povos 218| Século XXI, Revista de Ciências Sociais, v.3, nº 1, p.212-236, jan./jun. 2013 ISSN: 2236-6725 
indígenas" diminuiria em relação ao número previsto pelo Programa de Ações Afirmativas para o Vestibular 2013.

Tassinari e Tragtenberg (2012) destacam que a tentativa de adequação do Programa de Ações Afirmativas (PAA) à Lei 12.711/2012 trouxe a incômoda tarefa de utilizar as categorias do IBGE ("pretos", "pardos" e "indígenas"), juntamente com as categorias já utilizadas pelo PAA ("negros" e "pertencentes a povos indígenas"). Sabe-se que não se tratam de nomenclaturas equivalentes, devido à carga política que carregam estas últimas, uma vez que expressam não apenas a cor ou o fenótipo, mas o pertencimento étnico-racial. Do mesmo modo, os autores pontuam que a lei fala apenas em auto-declaração, enquanto o PAA prevê a verificação da auto-declaração de negros e de pertencentes a povos indígenas, mediante a apresentação presencial dos candidatos a uma Comissão de Validação das auto-declarações.

Conforme destacam Tassinari e Tragtenberg (2012), a Comissão de Acompanhamento e Avaliação do Programa de Ações Afirmativas propôs que a adequação acontecesse prevendo $20 \%$ das vagas, por curso, para candidatos oriundos de escola pública, ampliando a obrigatoriedade Lei de Cotas que previa para este ano somente 12,5\%. Assim, dos $20 \%$ das vagas reservadas, 6,25\% destinar-se-iam para candidatos com renda familiar per capita de até um salário-mínimo e meio; sendo 1,8\% para o segmento "pretos, pardos e indígenas". Somado a isto, permaneceriam as 10 vagas suplementares para indígenas e também a reserva de $10 \%$ das vagas para negros, que tenham cursado o ensino médio, preferencialmente, em escolas públicas. Sobre estas duas últimas modalidades de reserva de vagas, haveria a possibilidade de abarcar candidatos com outros percursos escolares e caberia o processo de validação de suas autodeclarações de "negros" e "pertencentes a povos indígenas" (Tassinari e TRagtenberg, 2012).

Dessa maneira, o Programa de Ações Afirmativas passou por uma reedição, aprovada no Conselho Universitário e expressa na Resolução Normativa N. ${ }^{\circ}$ 22/CUn/2012, de 29 junho de 2012. Estipulou-se uma reserva de $30 \%$ das vagas do vestibular, em cada curso de graduação da Universidade, sendo que destas $20 \%$ deverão ser ocupadas por candidatos que tenham cursado o ensino médio em 
instituições públicas de ensino; e 10\% por candidatos autodeclarados negros, que tenham cursado preferencialmente o ensino médio em instituições públicas de ensino.

Continua a existir o processo de validação da autodeclaração, através de comissão composta por representantes da UFSC e do movimento negro. De acordo com Tassinari e Tragtenberg (2012), a experiência dos primeiros cinco anos de existência do PAA/UFSC demonstrou que aproximadamente 5\% a 10\% dos candidatos autodeclarados "negros" e $16 \%$ dos candidatos autodeclarados "pertencentes a povos indígenas" não correspondiam ao perfil estipulado no PAA.

A reserva de vagas para candidatos pertencentes a povos indígenas foi limitada a "povos indígenas residentes no território nacional e transfronteiriços" e está assim expressa no Art. 10. da Resolução:

“Art. 10. (...) serão criadas 10 (dez) vagas suplementares no vestibular 2013, que serão preenchidas pelos candidatos melhor classificados nesse vestibular, observadas as seguintes condições:

$\S 1^{\circ}$ As vagas a que se refere o caput deste artigo serão criadas especificamente para este fim nos cursos em que houver candidatos aprovados, observado o limite de 3 (três) vagas por curso.

$\S 2 .^{\circ} \mathrm{O}$ número total de vagas a que se refere o caput deste artigo será ampliado, a cada ano, mediante a criação de três novas vagas, até perfazer o total de 22 vagas em 2017.

$\S 3 .^{\circ}$ Os candidatos a que se refere este artigo, interessados em participar na ação afirmativa de acesso aos cursos de graduação, deverão fazer a sua opção no ato de inscrição do vestibular”.(CUn/UFSC, 2012, p 04)

Tal como o caso de estudantes autodeclarados negros, os candidatos pertencentes a povos indígenas também passam por um processo de validação da autodeclaração por uma comissão específica. Porém, a Comissão de Acompanhamento e Avaliação do Programa de Ações Afirmativas destaca que o se está avaliando não o fenótipo ou a ascendência indígena, mas sim o pertencimento a um povo, o que também é aferido por correspondências de lideranças indígenas e/ou da Fundação Nacional do Índio (Funai). Da mesma forma que com can- 
didatos autodeclarados negros, dois candidatos que se autodeclararam indígenas, ao longo dos últimos cinco anos, não conseguiram comprovar seu pertencimento a um povo (Tassinari e Tragtenberg, 2012).

Assim, o Programa de Ações Afirmativas da UFSC buscou somar a Lei de Cotas à sua experiência de cinco anos de trabalho para possibilitar a democratização do acesso aos cursos superiores na instituição, fazendo as adequações necessárias. Como resultado, foi criada a Resolução Normativa N. o 26/CUn/2012, de 16 de outubro 2012, com vistas a adequar o PAA/UFSC à primeira Lei brasileira sobre Ações Afirmativas nas instituições federais de ensino superior (Lei 12.711/2012) e normas complementares (Decreto Presidencial $n^{0} 7.824 / 2012$, Portaria Normativa n ${ }^{\circ}$ 18/2012 e Resolução no 22/CUN/2012).

Em seguida apresentamos um panorama de dados quantitativos que nos auxiliam a compreender como a reserva de vagas para indígenas foi sendo ocupada no período de 2008 a 2012. Do mesmo modo, dialogando com informações oriundas de estudantes indígenas buscamos refletir sobre os limites e possibilidades presentes no cenário atual de inclusão de indígenas no ensino superior da UFSC.

\section{A PRESENÇA INDÍGENA NO ENSINO SUPERIOR DA UFSC}

Apresentamos abaixo uma tabela síntese detalhando o total de estudantes inscritos no vestibular desde 2008, quando ocorreu o primeiro vestibular com reserva de vagas específicas para indígenas, até o ingresso mais recente, vestibular 2013, com dados oficiais disponibilizados pela Comissão Permanente do Vestibular (COPERVE). A Tabela 1 apresenta dados que informam que no ano de 2008 houve apenas 7 inscritos, ocorrendo um aumento substantivo, no ano seguinte, para 14 inscritos em 2009. Contrariando as iniciativas de uma política de democratização do acesso com recortes socioeconômicos e étnico-raciais, em 2009 houve uma decisão institucional de alterar a linha de corte para aprovação, conforme será especificado adiante. $\mathrm{O}$ efeito mais grotesco desta decisão institucional foi o não preenchimento de vagas em, ao menos, nove cursos ofertados nos diferentes Campi e nas diferentes modalidades de ingresso na 
UFSC, quer pelo Programa de Ações Afirmativas ou pelo sistema geral. Particularmente, para o caso dos candidatos indígenas, a repercussão refletiu sobre o índice da aprovação e na diminuição dos pretendentes para os vestibulares nos anos seguintes. Isto explica, em alguma medida, a considerável diminuição do número de candidatos indígenas em 2010, com 7 inscritos e somente dois aprovados e classificados; e em 2011, com 3 inscritos e 2 aprovados e classificados. No ano de 2012, houve um importante aumento de candidatos, atingindo o número de 13 inscritos com 06 aprovados e cinco classificados. Esse aumento continuou em 2013, com 17 inscritos, 5 aprovados e 4 classificados. Entretanto, é um numero que expressa resultados bastante tímidos para uma política arrojada de inclusão.

Tabela 1 - Inscrição e classificação dos candidatos autodeclarados Indígenas pelo Programa de Ações Afirmativas 2008-2013

\begin{tabular}{|l|c|c|c|c|c|c|c|}
\hline & 2008 & 2009 & 2010 & 2011 & 2012 & 2013 & Total \\
\hline Inscritos & 07 & 14 & 07 & 03 & 13 & 17 & 61 \\
\hline Aprovados & 03 & 02 & 01 & 02 & $06 * * *$ & $05^{* * *}$ & 20 \\
\hline Classificados & 03 & 02 & $02 * *$ & 02 & 05 & 04 & 18 \\
\hline Matricula Inicial & 03 & $01 *$ & 02 & 02 & $02 *$ & 04 & 14 \\
\hline $\begin{array}{l}\text { Vagas Previstas } \\
\text { (Suplementares) }\end{array}$ & 05 & 06 & 07 & 08 & 09 & 10 & 45 \\
\hline $\begin{array}{l}\text { Relação vagas } \\
\text { previstas e criadas }\end{array}$ & $60 \%$ & $16,6 \%$ & $28,5 \%$ & $25 \%$ & $22,2 \%$ & $40 \%$ & $28,5 \%$ \\
\hline
\end{tabular}

* Um candidato teve a autodeclaração não validada

** Houve uma classificação por vaga remanescente do ENEM

*** Mais aprovados em Medicina do que o número máximo de vagas previsto por curso Fonte: NEPI/CFH/UFSC - 2013

Os quadros-síntese 1 e 2, apresentados abaixo, informam-nos além dos cursos mais procurados, os tipos de reprovações mais recorrentes nos vestibulares ao longo dos 5 primeiros anos (os dados de 2013 não puderam ser acrescidos à análise). Quando analisados os dados sobre o desempenho dos candidatos e o motivo da reprovação, fica bastante evidente o impacto das alterações bruscas ocorridas no vestibular em 2009, como sinalizado atrás. Com as alterações, aumentou o desempenho mínimo para o candidato ser considerado aprovado no vestibular: na Redação a nota mínima passou de 3,0 
para 4,0; em Língua Portuguesa e Literatura a nota passou igualmente de 3,0 para 4,0; bem como a alteração de 20 para 24 pontos mínimos no conjunto das sete demais disciplinas.

A Comissão de Acompanhamento e Avaliação do Programa de Ações Afirmativas elaborou um relatório analisando essa questão e solicitando que a nota de corte voltasse a ser o desempenho mínimo historicamente utilizado nos vestibulares anteriores para todos os candidatos ao concurso vestibular. Isso foi modificado nos vestibulares de 2011 e 2012, representando um considerável aumento nas aprovações (66\% em 2011 e 46\% em 2012). Isso ressalta a importância de um critério diferenciado no vestibular para indígenas, especialmente considerando que a língua portuguesa, para a maioria, é uma língua segunda língua.

Quadro 1 - Estudantes indígenas no vestibular UFSC - 2008-2012 Identificação dos motivos de reprovação por ano, curso e grupo étnico

\begin{tabular}{|c|c|c|c|}
\hline Ano & Curso & Ocorrência & Grupo étnico \\
\hline \multirow{4}{*}{2008} & Enfermagem & Reprovado por falta & Tukano \\
\hline & Pedagogia & $\begin{array}{l}\text { Reprovado por zero e insu- } \\
\text { ficiência de acertos }\end{array}$ & Xokleng \\
\hline & $\begin{array}{l}\text { Serviço social - } \\
\text { noturno }\end{array}$ & Reprovado por falta & Xokleng \\
\hline & $\begin{array}{l}\text { Artes cênicas - te- } \\
\text { atro - not. }\end{array}$ & $\begin{array}{l}\text { Reprovado por insuficiên- } \\
\text { cia de acertos }\end{array}$ & Xokleng \\
\hline \multirow{12}{*}{2009} & Direito - noturno & Reprovado por falta & Guarani \\
\hline & Direito - noturno & Reprovado por falta & Guarani \\
\hline & Medicina & $\begin{array}{l}\text { Reprovado em L. Port. e } \\
\text { insuficiência de acertos }\end{array}$ & Tikuna \\
\hline & Medicina & $\begin{array}{l}\text { Reprovado em L. Port. e } \\
\text { insuficiência de acertos }\end{array}$ & Tikuna \\
\hline & Medicina & $\begin{array}{l}\text { Reprovado no conjunto } \\
\text { das Discursivas }\end{array}$ & Xokleng \\
\hline & Medicina & Reprovado em português & Kaingang \\
\hline & Odontologia & Reprovado por falta & Kaingang \\
\hline & Pedagogia & Reprovado por falta & Guarani \\
\hline & Psicologia - bel/lic & $\begin{array}{l}\text { Reprovado por zero,em L. } \\
\text { Port. e insuf. de acertos }\end{array}$ & Guarani \\
\hline & $\begin{array}{l}\text { História - diurno - } \\
\text { bel/lic }\end{array}$ & $\begin{array}{l}\text { Reprovado em L. Port. e } \\
\text { insuficiência de acertos }\end{array}$ & Guarani \\
\hline & $\begin{array}{l}\text { Filosofia - noturno } \\
\text { - bel/lic }\end{array}$ & $\begin{array}{l}\text { Reprovado em L. Port. e } \\
\text { insuficiência de acertos }\end{array}$ & Guarani \\
\hline & $\begin{array}{l}\text { Letras-1.Port.e lit. } \\
\text { Ling.Port }\end{array}$ & Reprovado por falta & Guarani \\
\hline
\end{tabular}




\begin{tabular}{|c|c|c|c|}
\hline Ano & Curso & Ocorrência & Grupo étnico \\
\hline \multirow{6}{*}{2010} & Enfermagem & Reprovado por falta & Kaingang \\
\hline & Medicina & $\begin{array}{l}\text { Reprovado por zero e insu- } \\
\text { ficiência de acertos }\end{array}$ & Xokleng \\
\hline & Medicina & $\begin{array}{l}\text { Reprovado no conjunto } \\
\text { das Discursivas }\end{array}$ & Kaingang \\
\hline & Medicina & Reprovado por falta & Guarani \\
\hline & Agronomia & $\begin{array}{l}\text { Reprovado no conjunto } \\
\text { das Discursivas e Redação }\end{array}$ & Xokleng \\
\hline & Agronomia & $\begin{array}{l}\text { Reprovado em L. Port. e } \\
\text { insuficiência de acertos }\end{array}$ & Guarani \\
\hline 2011 & Agronomia & $\begin{array}{l}\text { Reprovado por zero em } \\
\text { uma ou mais disciplinas }\end{array}$ & Xokleng \\
\hline \multirow{7}{*}{2012} & Direito - noturno & $\begin{array}{l}\text { Reprovado no conjunto } \\
\text { das Discursivas }\end{array}$ & Xokleng \\
\hline & Enfermagem & $\begin{array}{l}\text { Reprovado no conjunto } \\
\text { das Discursivas e Redação }\end{array}$ & Guarani \\
\hline & Medicina & Reprovado por falta & Pankararé \\
\hline & Medicina & $\begin{array}{l}\text { Reprovado por zero em } \\
\text { uma ou mais disciplinas }\end{array}$ & Kaingang \\
\hline & $\begin{array}{l}\text { Sistemas de infor- } \\
\text { mação /not }\end{array}$ & Reprovado na redação & Tupinambá \\
\hline & $\begin{array}{l}\text { Antropologia - bel } \\
\text { - diurno }\end{array}$ & $\begin{array}{l}\text { Reprovado no conjunto } \\
\text { das Discursivas e Redação }\end{array}$ & Xokleng \\
\hline & $\begin{array}{l}\text { Educação Física - } \\
\text { diurno }\end{array}$ & $\begin{array}{l}\text { Reprovado no conjunto } \\
\text { das Discursivas }\end{array}$ & Xokleng \\
\hline
\end{tabular}

O quadro acima nos aproxima das percepções dos estudantes indígenas sobre uma de suas dificuldades em face dos modelos de provas, bem como dos tipos de habilidades e conhecimentos esperados dos candidatos ao vestibular: problemas com redação, pois português, em geral, é a segunda língua. A significativa incidência de reprovação nas questões associadas à Língua Portuguesa e Literatura em Língua Portuguesa (7), ao conjunto das questões discursivas (6) e à Redação (3), com 16 ocorrências; falta (10); insuficiência de acertos (9); e zero em uma ou mais disciplinas (4) são ocorrências que aparecem na sequência. Estes dados indicam a importância de reconsiderar novas modelagens de seleção de ingresso como, por exemplo, instituição de vestibular específico, para alcançar maior efetividade na política institucional de inclusão deste segmento no ensino superior.

Os cursos mais demandados pelos candidatos indígenas fo- 
ram: Medicina (14 inscritos), Direito Noturno/Diurno (6), Agronomia (5), Enfermagem (4), Pedagogia (2), Sistemas de Informação (2). Os demais cursos tiveram um inscrito ao longo do período: Engenharia Sanitária, Serviço Social, Artes Cênicas, Odontologia, Psicologia, História, Filosofia, Letras/Português, Arquitetura e Urbanismo, Antropologia e Educação Física.

Observa-se, a partir do Quadro 2, que, dentre os 15 estudantes aprovados e 14 classificados no vestibular, ao longo destes 5 anos, para ocupar vagas suplementares, somente 10 efetivaram matrícula, sendo que 3 estudantes não se apresentaram à banca de validação da autodeclaração e 2 não obtiveram a autodeclaração validada por não terem apresentado elementos que permitissem vincular seu pertencimento a um povo indígena, conforme define a Resolução.

Quadro 2 - Estudantes indígenas e matrícula na UFSC 2008-2012

Situação na matrícula e atual por ano, curso e grupo étnico

\begin{tabular}{|c|c|c|c|c|c|}
\hline Ano & Curso & $\begin{array}{l}\text { Desempe- } \\
\text { nho } \\
\text { no vesti- } \\
\text { bular }\end{array}$ & $\begin{array}{l}\text { Situação na } \\
\text { Matrícula }\end{array}$ & Situação atual & $\begin{array}{l}\text { Grupo } \\
\text { étnico }\end{array}$ \\
\hline \multirow{3}{*}{2008} & $\begin{array}{l}\text { Direito - no- } \\
\text { turno }\end{array}$ & Classificado & $\begin{array}{l}\text { Matricula } \\
\text { efetivada }\end{array}$ & $\begin{array}{l}\text { Matricula re- } \\
\text { gular }\end{array}$ & Xokleng \\
\hline & Enfermagem & Classificado & $\begin{array}{l}\text { Matricula } \\
\text { efetivada }\end{array}$ & $\begin{array}{c}\text { Matrícula } \\
\text { trancada } \\
\text { Cursa Medici- } \\
\text { na/2010* }\end{array}$ & $\begin{array}{l}\text { Kain- } \\
\text { gang }\end{array}$ \\
\hline & $\begin{array}{l}\text { Engenharia sa- } \\
\text { nit. e ambiental }\end{array}$ & Classificado & $\begin{array}{l}\text { Matricula } \\
\text { efetivada }\end{array}$ & $\begin{array}{l}\text { Matrícula } \\
\text { trancada** }\end{array}$ & Xokleng \\
\hline \multirow[t]{2}{*}{2009} & $\begin{array}{l}\text { Direito - no- } \\
\text { turno }\end{array}$ & Classificado & $\begin{array}{l}\text { Matricula } \\
\text { efetivada }\end{array}$ & $\begin{array}{l}\text { Matrícula re- } \\
\text { gular, em vias } \\
\text { de formatura } \\
\text { Aprovado na } \\
\text { OAB }\end{array}$ & Xokleng \\
\hline & Medicina & Classificado & $\begin{array}{l}\text { Auto-decla- } \\
\text { ração não } \\
\text { validada }\end{array}$ & $\begin{array}{l}\text { Vaga cance- } \\
\text { lada }\end{array}$ & $\begin{array}{l}\text { Xavante/ } \\
\text { Kadiweu }\end{array}$ \\
\hline \multirow[t]{2}{*}{2010} & Medicina & $\begin{array}{c}\text { Reprovado/ } \\
\text { Classifica- } \\
\text { do vagas } \\
\text { ENEM }\end{array}$ & $\begin{array}{l}\text { Matricula } \\
\text { efetivada }\end{array}$ & $\begin{array}{l}\text { Matrícula re- } \\
\text { gular } \\
\text { *Matrícula } \\
\text { Trancada em } \\
\text { Enferma- } \\
\text { gem } / 2008\end{array}$ & $\begin{array}{l}\text { Kain- } \\
\text { gang }\end{array}$ \\
\hline & Agronomia & Classificado & $\begin{array}{l}\text { Matricula } \\
\text { efetivada }\end{array}$ & $\begin{array}{l}\text { Matrícula re- } \\
\text { gular }\end{array}$ & $\begin{array}{l}\text { Wapixa- } \\
\text { na }\end{array}$ \\
\hline
\end{tabular}




\begin{tabular}{|c|c|c|c|c|c|}
\hline Ano & Curso & $\begin{array}{l}\text { Desempe- } \\
\text { nho } \\
\text { no vesti- } \\
\text { bular }\end{array}$ & $\begin{array}{l}\text { Situação na } \\
\text { Matrícula }\end{array}$ & Situação atual & $\begin{array}{l}\text { Grupo } \\
\text { étnico }\end{array}$ \\
\hline \multirow[b]{2}{*}{2011} & Medicina & Classificado & $\begin{array}{l}\text { Matricula } \\
\text { efetivada }\end{array}$ & $\begin{array}{l}\text { Matrícula } \\
\text { trancada }\end{array}$ & Xokleng \\
\hline & $\begin{array}{l}\text { Sistemas de in- } \\
\text { formação - not }\end{array}$ & Classificado & $\begin{array}{l}\text { Matricula } \\
\text { efetivada }\end{array}$ & $\begin{array}{l}\text { Matrícula re- } \\
\text { gular }\end{array}$ & Ticuna \\
\hline \multirow{6}{*}{2012} & Medicina & Classificado & $\begin{array}{l}\text { Matricula } \\
\text { efetivada }\end{array}$ & $\begin{array}{l}\text { Matrícula re- } \\
\text { gular }\end{array}$ & Xokleng \\
\hline & Medicina & Classificado & $\begin{array}{l}\text { Não compa- } \\
\text { receu }\end{array}$ & $\begin{array}{l}\text { Vaga cance- } \\
\text { lada }\end{array}$ & Krenak \\
\hline & Medicina & $\begin{array}{l}\text { Não classi- } \\
\text { ficado }\end{array}$ & $\begin{array}{l}\text { Não convo- } \\
\text { cado }\end{array}$ & & $\begin{array}{l}\text { Kain- } \\
\text { gang }\end{array}$ \\
\hline & $\begin{array}{l}\text { Arquitetura e } \\
\text { urbanismo }\end{array}$ & Classificado & $\begin{array}{l}\text { Auto-decla- } \\
\text { ração não } \\
\text { validada }\end{array}$ & $\begin{array}{l}\text { Vaga cance- } \\
\text { lada }\end{array}$ & $\begin{array}{c}\text { Mapu- } \\
\text { che/ } \\
\text { Guarani }\end{array}$ \\
\hline & Direito - diurno & Classificado & $\begin{array}{l}\text { Matrícula } \\
\text { efetivada }\end{array}$ & $\begin{array}{l}\text { Matrícula re- } \\
\text { gular }\end{array}$ & Xokleng \\
\hline & Agronomia & Classificado & $\begin{array}{l}\text { Não compa- } \\
\text { receu }\end{array}$ & $\begin{array}{l}\text { Vaga cance- } \\
\text { lada } \\
\text { **Matrícula } \\
\text { trancada em } \\
\text { Eng.Sanitária }\end{array}$ & Xokleng \\
\hline
\end{tabular}

A respeito da situação no curso, observa-se que, dentre os 9 indígenas matriculados (ressalta-se que uma mesma candidata matriculou-se duas vezes), 2 estão atualmente com a matrícula trancada e somente 7 estão cursando regularmente. Destes, o acadêmico que ingressou no segundo ano do Programa de Ações Afirmativas em Direito, informou já ter sido aprovado no concurso da Ordem dos Advogados do Brasil (OAB) antes mesmo de sua formatura, que poderia ocorrer já no início de 2013, mas que está sendo adiada em virtude de compromissos de trabalho. Este resultado demonstra a enorme importância do sistema de inclusão dos indígenas promovido pelo programa das Ações Afirmativas.

A respeito da etnia, dentre os matriculados há uma predominância dos Xokleng (5 inscritos), seguido dos Kaingang (2 inscritos) e um inscrito das demais etnias (Wapixana e Ticuna). No entanto, se considerarmos o número de inscritos, observamos um número alto de inscrições de candidatos Guarani (11 inscrições), abaixo do número de inscrições dos Xokleng (14 inscrições), mas acima dos Kaingang (8 inscrições). 
No vestibular 2013 da UFSC foram 17 os candidatos inscritos que se autodeclararam indígenas, o correspondente a $0,05 \%$ do total de inscrições. Destes, cinco foram aprovados e 4 classificados. Foi o ano com maior número de indígenas inscritos, porém, a média de aprovação e classificação permaneceu a mesma dos anos anteriores. Tal aumento do número de inscrições deveu-se principalmente ao trabalho desenvolvido pelo Programa de Extensão "Promoção da Igualdade Étnico-Racial no Ensino Superior”, coordenado pela Professora Antonella Tassinari, desenvolvido no âmbito do Núcleo de Estudos de povos Indígenas, em parceria com Comissão de Acompanhamento e Avaliação do Programa de Ações Afirmativas e com o Grupo de Pesquisa "Escolarização, práticas docentes e conhecimentos pedagógicos" do Centro de Ciências da Educação da UFSC. Este programa visa, dentre outras ações, a realização de oficinas de debates sobre Ações Afirmativas em Escolas localizadas em Terras Indígenas. Os encontros realizados em terras indígenas guarani, kaingang e xokleng, envolvendo lideranças, estudantes de ensino médio e comunidade destas etnias, permitiram que os participantes pudessem tirar dúvidas sobre o processo de inscrição e desenvolvimento do vestibular, além de pontuarem aspectos a serem revistos na seleção de estudantes indígenas.

Entendemos que as oficinas impulsionaram um número de inscrições maior, mas este não foi o único resultado significativo. Os relatórios dos responsáveis por mediar estas discussões somamse aos dados quantitativos analisados até o momento e nos indicam a importância de um vestibular diferenciado, que garanta o êxito de populações indígenas com experiências mais recentes de escolarização, como é o caso dos Guarani, população com o maior número de inscritos e menor índice de aprovação.

\section{ACESSO, INGRESSO E PERMANÊNCIA: VARIÁVEIS DE UM PROCESSO DE INCLUSÃO}

Percebemos que o não preenchimento da maioria das vagas destinadas a estudantes indígenas na UFSC deve-se menos ao acesso à in- 
formação sobre o desenvolvimento do Programa de Ações Afirmativas, do que ao formato do vestibular atual. A existência de "cotas para indígenas" não é exatamente uma novidade. Porém, a maioria dos indígenas que participaram das oficinas de debate sobre ações afirmativas, acima mencionadas, desconheciam como funcionava a política de reserva de vagas na Universidade Federal de Santa Catarina, principalmente quanto ao número de vagas por curso, assistência estudantil, etc.

Em oficina realizada na aldeia de Morro dos Cavalos, em Palhoça/SC, um dos professores guarani, que leciona na escola da comunidade, relatou já ter realizado um vestibular da UFSC, porém sem êxito. Desta experiência compartilhou conosco a impressão de que o formato da prova se torna difícil, uma vez as respostas são assinaladas em opção somatória. Provas de múltipla escolha, em sua opinião, tendem a facilitar a interpretação porque o aluno visualiza a questão e busca uma única resposta para a mesma, especialmente quando esta resposta é expressa em uma segunda língua.

Este mesmo docente corrobora com as interpretações iniciais que os dados quantitativos nos apresentam, no que tange à questão da língua portuguesa. Segundo ele a língua portuguesa é o maior desafio que os guarani enfrentam no vestibular. Isso porque, apresenta-se como a disciplina considerada mais difícil pelos alunos da escola. Prova disso seria a percepção de que não se vê nenhum jovem pretendendo ter uma profissão em que o domínio da língua portuguesa seja primordial, como por exemplo a área de Letras.

Também os estudantes já matriculados na UFSC, quando consultados sobre o Programa de Ações Afirmativas, elencaram os seguintes aspectos como problemáticos para o público indígena:

1. altos custos para realização da inscrição;

2. muita burocracia para obtenção da isenção do pagamento da taxa de inscrição do Vestibular;

3. falta de preparação para enfrentar um vestibular;

4. problemas com redação, pois português, em geral é segunda língua;

5. formação deficitária no Ensino Fundamental e Médio; 
6. extrema dificuldade para a obtenção de bolsa permanência (documentos exigidos para a inscrição no cadastro socioeconômico);

7. não garantia de bolsa-auxílio da Fundação Nacional do Índio, diferente do que acontece em outros estados;

8. falta de vagas na moradia estudantil;

9. dificuldade com transporte até a Universidade;

10. questão da divulgação do vestibular e das vagas para alunos indígenas - necessidade de visita às aldeias de Santa Catarina com Ensino Médio para divulgação;

11. impossibilidade de realizar transferência das vagas suplementares a outras Universidades, mesmo com Ações Afirmativas para indígenas;

12. falta de apoio institucional;

13. desconhecimento da dinâmica acadêmica;

14. sentem falta da família, solidão.

A respeito da trajetória escolar dos estudantes matriculados, até 2010 só havia egressos de escolas públicas de contexto urbano. Somente a partir de 2011 começaram a ingressar estudantes oriundos de escolas indígenas e residentes nas aldeias, sendo que um deles já trancou matrícula. Observa-se, portanto, que o Programa de Ações Afirmativas da UFSC não está conseguindo acolher os estudantes indígenas formados em suas aldeias, mas apenas aqueles já com experiência de residência em contexto urbano. A esse respeito, os candidatos Guarani residentes em aldeias próximas a Florianópolis, consideram que o principal problema não é a falta de divulgação, mas a ausência de um vestibular específico para indígenas, como vem ocorrendo em outras instituições. Alegam que todo o processo, desde a solicitação de isenção de taxa de inscrição até a realização das provas, é inacessível para os candidatos indígenas residentes em aldeias.

Uma das atividades do Projeto de Extensão mencionado acima consistiu em oferecer oficina de apoio para a realização das inscrições no Vestibular 2013 na aldeia de Morro dos Cavalos, em Palhoça/SC. Mesmo havendo na escola da aldeia uma sala com vários computado- 
res, o acesso à internet é limitado e intermitente, de forma que não foi possível completar as inscrições durante a oficina. Como essa situação se repete nas demais aldeias indígenas do Estado, ficou evidente que a inscrição on-line é impeditiva para a participação dos candidatos indígenas, sendo necessária uma forma alternativa para essa inscrição, como a possibilidade de utilizar formulários impressos.

A respeito do trancamento, o motivo alegado pelo estudante de Engenharia Sanitária foi necessidade de trabalho e sustento da família, como vigia noturno, impedindo o bom rendimento nas provas, especialmente nas de cálculo. No entanto, o mesmo estudante prestou vestibular outras duas vezes para Agronomia, tendo sido aprovado em 2012, mas não realizando a matrícula. Essa situação indica que um apoio mais atento a cada caso poderia garantir um melhor aproveitamento dessas vagas.

Em relação à estudante de Medicina, a aluna indígena alegou que o trancamento se deveu à mudança de sua família para outra aldeia na região metropolitana de Porto Alegre - RS e que buscaria transferência de sua vaga para a Universidade Federal do Rio Grande do Sul (UFRGS). Isso se soma ao fato de que os estudantes indígenas da UFRGS encontram maior apoio da Funai para a permanência na universidade. A estudante também informou que estava enfrentando vários problemas que a estavam desestimulando de prosseguir, entre eles, considera que sua formação em Química e Biologia no Ensino Médio foi insuficiente para acompanhar o curso, dificultando seu desempenho em várias disciplinas no âmbito das ciências naturais.

Outro dado importante sobre a permanência dos estudantes indígenas é a importância de se sentirem amparados por um grupo de colegas com experiências semelhantes, como ocorre nos cursos de Licenciatura Indígena. No último ano, percebeu-se uma mobilização de lideranças indígenas no Estado de Santa Catarina, para reivindicar uma segunda turma do Curso de Licenciatura Intercultural Indígena do Sul da Mata Atlântica da UFSC?. Tal postura se justifica

\footnotetext{
${ }^{7}$ Esse curso de licenciatura é organizado com base na Pedagogia da Alternância, dividido em "tempo universidade", que são etapas de aulas presenciais condensadas em três semanas no âmbito da universidade; e "tempo comunidade", período em que os estudantes permanecem em suas Terras Indígenas, desenvolvendo pesquisas específicas solicitadas por cada disciplina nos períodos de "tempo universidade". As turmas, com cerca de quarenta alunos em cada, são separadas por etnia: Kaingang, Guarani e Xokleng.
}

230| Século XXI, Revista de Ciências Sociais, v.3, nº 1, p.212-236, jan./jun. 2013 ISSN: 2236-6725 
pela necessidade de formação de professores indígenas para atuar nas escolas localizadas em suas aldeias. Porém, ao mesmo tempo em que se nota um número expressivo de indígenas que desejam atuar na docência, visualizamos também algumas pessoas que pretendem ingressar no curso, não porque gostariam de atuar como professores, mas porque entendem que a Licenciatura Intercultural Indígena lhes oferece mais garantias de ingresso e permanecia na Universidade.

Muitos relatos dos estudantes indígenas que ingressaram na UFSC assemelham-se a informações coletadas nas oficinas desenvolvidas pelo Programa de Extensão em aldeias de Santa Catarina. Problemas em afastar-se da família e da comunidade, dificuldades econômicas e sentimento de falta de preparo para realização da prova e, mesmo para quem ingressa, para acompanhar os cursos escolhidos são os principais pontos em comum. Há de se considerar que a relação que estudantes indígenas, principalmente aqueles que vivem em aldeias, estabelecem com o urbano e com a própria universidade diferem de forma significativa das relações que estudantes não-indígenas mantêm com estes contextos.

O ideal de sair de casa para estudar e alcançar autonomia financeira e independência pessoal, que geralmente motiva os estudantes universitários em busca de uma carreira profissional, não necessariamente é o que mobiliza os estudantes indígenas. Estudar para ter uma profissão e um bom salário é uma meta que vai ao encontro das práticas sociais das chamadas sociedades complexas e das camadas médias urbanas. Esta lógica centrada nos projetos individuais, na manutenção da família nuclear, na preparação para o mercado de trabalho nos moldes capitalistas, não é a mesma que tem direcionado os estudantes indígenas para o Ensino Superior, mesmo que a busca por profissionalização siga as mesmas trilhas dos estudantes não indígenas.

Considerar a solidão e a falta da família como uma barreira e um motivo de evasão pode parecer estranho no contexto universitário, onde a autonomia, a individualidade e a independência são características valorizadas e estimuladas. Porém, para pessoas oriundas de sociedades tradicionais, em que o parentesco tem profunda influencia na vida produtiva, na organização política e nas dinâmi- 
cas de produção e circulação de conhecimentos, por certo afastar-se da família e da comunidade é uma tarefa extremamente difícil.

Deste modo, ingressar em um curso superior possui significados muito distintos para a maioria dos estudantes indígenas. Sobre o sentimento de não dominar determinados conteúdos escolares, há um ponto que precisa ser considerado: a educação escolar indígena não é a mesma educação escolar não indígena e nem se pretende que seja. É certo que na trajetória de vida dos estudantes indígenas que ingressaram na UFSC encontraremos as mais diversas razões para cada um pensar que o vestibular é uma dificuldade. Mesmo assim, não se pode pensar que levar aos alunos a oportunidade de acessar os conteúdos privilegiados pelo vestibular resolveria o problema. Isso porque estarse-ia andando na contramão de todas as discussões sobre educação intercultural para os povos indígenas. Cabe lembrar que desde 1988 os povos indígenas têm assegurado o direito a uma educação própria, diferenciada, intercultural e bilíngue, que contemple seus processos próprios de aprendizagem (Brasil, 1988; 1996; 2001). E se o vestibular realizado para alunos não indígenas não vai ao encontro destas premissas, faz-se necessário reforçarmos a ideia de um vestibular específico para candidatos pertencentes a povos indígenas, a exemplo do que já acontece em algumas universidades brasileiras.

Por fim, cabe destacar alguns pontos em relação ao processo de validação da autodeclaração de indígenas. Tal atividade tem sido dirigida por comissões formadas por especialistas nas populações indicadas pelos candidatos aprovados em suas fichas de inscrição. As bancas informaram que os dois candidatos que não tiveram a autodeclaração validada não apresentaram nenhum dado ou documento que permitisse verificar seu pertencimento a um povo. Nos dois casos, o pertencimento étnico alegado no dia da entrevista foi diferente daquele informado na ficha de inscrição. Um dos casos fez referência aos Mapuche, população indígena do Chile. Foi isso que levou a comissão de validação a sugerir a necessidade de especificar que o Programa de Ações Afirmativas da UFSC atenda as populações indígenas "residentes no território nacional ou transfronteiriços".

Para amparar a atividade da comissão de validação das autode- 
clarações de indígenas, as fichas de inscrição no vestibular têm solicitado informações dos candidatos quanto ao grupo indígena a que pertence, à sua situação linguística, à descrição da sua história de vida, às expectativas em relação ao curso de deseja cursar, conforme disposto no artigo 10 da Resolução Normativa n.008/CUN/2007. Embora essas informações sejam importantes, o resultado é que os candidatos às vagas para indígenas são obrigados a preencher um formulário qualitativo que não é exigido dos demais, tornando-se outro fator a inibir a inscrição. Desse modo, percebe-se que não apenas a prova do vestibular precisa ser revista, mas o próprio processo de inscrição precisa ser reformulado de forma a ser convidativo aos candidatos indígenas.

\section{CONSIDERAÇÕES FINAIS}

Como resultado do diagnóstico do Programa de Ações Afirmativas da UFSC voltado para indígenas, conclui-se que há necessidade de melhorias, tanto para a efetivação do preenchimento das vagas, quanto para a garantia da permanência dos estudantes no Ensino Superior. Se consideramos que 61 indígenas se candidataram às 45 vagas oferecidas para indígenas de 2008 a 2013, somente 14 efetivaram sua matrícula e apenas 10 estão freqüentando a universidade $^{8}$, verificamos a necessidade urgente de revisão dos mecanismos de Ações Afirmativas para indígenas na UFSC.

Dessa forma, considerando a importância de se compreender o conjunto de problemas que envolvem os indígenas na universidade, incluindo o fato de que mesmo aqueles poucos que têm conseguido entrar, apresentam dificuldades com a sua permanência, destacamos a necessidade de apoio institucional em vários níveis. Estratégias que auxiliem os estudantes indígenas a acompanhar as aulas; ampliação dos programas de assistência estudantil no que se refere à transporte e moradia; e valorização dos conhecimentos nativos e/ou oriundos da trajetória escolar desses estudantes, são iniciativas de suma importância para viabilizar a democratização do acesso ao ensino superior.

\footnotetext{
${ }^{8}$ Observa-se que uma mesma pessoa se matriculou duas vezes, há dois trancamentos e um candidato deverá ingressar somente no segundo semestre de 2013.

233| Século XXI, Revista de Ciências Sociais, v.3, nº 1, p.212-236, jan./jun. 2013 ISSN: 2236-6725
} 
Do mesmo modo, facilitar o acesso às informações sobre o funcionamento do Programa de Ações Afirmativas, às formas de assistência estudantil existentes e à solicitação de isenção da taxa do vestibular são elementos que podem potencializar o aumento do número de candidatos indígenas. Somado a isto, reforçamos mais uma vez a importância de um vestibular específico que dialogue com as políticas de educação escolar indígena presentes na educação básica, de modo a viabilizar, também no âmbito da universidade, espaçostempos de aprendizagem e trocas pautadas na interculturalidade.

\section{REFERÊNCIAS}

AMARAL, Wagner Roberto do. As Trajetórias dos Estudantes Indígenas nas Universidades Estaduais do Paraná: Sujeitos e Pertencimentos. 2010. Tese (Doutorado em Educação) Programa de Pós-Graduação em Educação, Universidade Federal do Paraná, Curitiba.

BRASIL. Constituição da República Federativa do Brasil de 1988. Constituição da República Federativa do Brasil. Presidente da República; Casa Civil; Subchefia para Assuntos Jurídicos, Brasília, DF, 05 de outubro de 1988. Disponível em <http://www.planalto. gov.br/ccivil-03/constituição/constitui\%c3\%A7ao.htm>. Acesso em: 10 de janeiro de 2008.

BRASIL. Lei Federal n. 9.394/96. Lei de Diretrizes e Bases da Educação Nacional. LDBEN, 1996. Disponível em <www.regra.com.br/ educação/novaldb.hat>. Acesso em: 23 de janeiro de 2008.

BRASIL. Plano Nacional de Educação - PNE. Disponível em portal.mec. gov.br/arquivos/pdf/pne.pdf. Acesso em 09 de junho de 2008.

BRASIL. LEI $N^{o}$ 12.711, DE 29 DE AGOSTO DE 2012. Dispõe sobre o ingresso nas universidades federais e nas instituições federais de ensino técnico de nível médio e dá outras providências. Brasília, 29 de agosto de 2012 .

CONSELHO NACIONAL DE EDUCAÇÃO. Parecer $N^{o} .3 C N E$, de 17 de junho de 2004. Assunto Diretrizes Curriculares Nacionais para a Educação das Relações Étnico-Raciais e para o Ensino de História e Cultura Afro-Brasileira e Africana. Brasília: CNE, 2004. 
17 de junho de 2004. Institui Diretrizes Curriculares Nacionais para a Educação das Relações Étnico-Raciais e para o Ensino de História e Cultura Afro-Brasileira e Africana. Brasília: CNE, 2004.

CAJUEIRO, Rodrigo. Os povos indigenas em instituições de ensino superior públicas federais e estaduais do Brasil: levantamento provisório de ações afirmativas e de licenciaturas interculturais Projeto Trilhas de Conhecimento: o Ensino Superior de Indígenas no Brasil. Rio de Janeiro: LACED/Museu Nacional, 2007.

RIO DE JANEIRO. Lei 3524/00, de 28 de dezembro de 2000, estado do Rio de janeiro. Dispõe sobre os critérios de seleção e admissão de estudantes da rede pública estadual de ensino em universidades públicas estaduais e dá outras providencias. Rio de Janeiro: Assembléia Legislativa/ Governo do Estado, 2000 - revogada em 2003.

RIO DE JANEIRO. Lei $N^{o} 4151$, de 04 de Setembro de 2003. Institui nova disciplina sobre o sistema de cotas para ingresso nas universidades públicasestaduaise dáoutrasprovidências. RiodeJaneiro: Assembléia Legislativa/ Governo do Estado, 2000. Disponível em http://alerjln1. alerj.rj.gov.br/contlei.nsf/b24a2da5a077847c032564f4005d4bf2/ e50b5bf653e6040983256d9c00606969?OpenDocument.

SOUZA LIMA, Antonio Carlos e BARROSO-HOFFMANN, Maria (Orgs.). 2007. Desafios Para uma Educação Superior Para os Povos Indígenas no Brasil: Políticas Públicas de ação afirmativa e direitos culturais diferenciados. LACED/Museu Nacional, Rio de Janeiro, 2007.

TASSINARI, Antonela Maria Imperatriz; TRAGTENBERG, Marcelo. O Haiti é ou não é aqui? A Lei de Cotas e a inclusão étnicoracial na UFSC. Disponível em http://nepieduca.wordpress.com/: Florianópolis, 2012.

TRAGTENBERG, Marcelo, BOING, Alexandra, BOING, Antonio, TASSINARI, Antonella. Impacto das ações afirmativas na Universidade Federal de Santa Catarina (2008-2011). In: SANTOS, Jocélio Teles dos (Org.). O impacto das cotas nas universidades brasileiras (2004-2012). Salvador: Centro de Estudos Afroorientais, 2013.

UNIVERSIDADE FEDERAL DE SANTA CATARINA. Resolução Normativa $N^{o}$ 008/CUN/2007, de 10 de julho de 2007. Cria o "Programa de Ações Afirmativas" da Universidade Federal de Santa Catarina. Florianópolis, 2012. Disponível em http://acoes- 
afirmativas.ufsc.br/legislacao/

UNIVERSIDADE FEDERAL DE SANTA CATARINA. Resolução

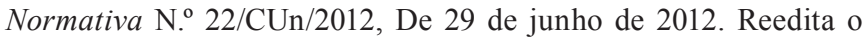
Programa de Ações Afirmativas da

UNIVERSIDADE FEDERAL DE SANTA CATARINA. Florianópolis, 2012. Disponível em http://acoes-afirmativas.ufsc.br/legislacao/

UNIVERSIDADE FEDERAL DE SANTA CATARINA. Resolução Normativa N. $^{\circ}$ 26/CUn/2012, de 16 de outubro 2012. Adequa o Programa de Ações Afirmativas da Universidade Federal de Santa Catarina a Lei 12.711/2012 e normas complementares. Florianópolis, 2012. Disponível em http://acoes-afirmativas.ufsc.br/legislacao/

Recebido: 10/05/2013

Aprovado: 12/07/2013 